\title{
Thinking on the Design of Planning and Preparation Steps during Site Design
}

\author{
Rong $\operatorname{Han}^{1}$,Yujie Xin ${ }^{1}$, Lu Ding ${ }^{2}$ and Yang $\mathrm{Hu}^{3}$ \\ ${ }^{1}$ Art school of Jiangsu University, No. 301, Xuefu Road, Zhenjiang City, Jiangsu Prov, China \\ ${ }^{2}$ University of Idaho, 1634 S main st, Apt315 Moscow ID 83843, United States \\ ${ }^{3}$ Art school of Jiangsu University, No. 301, Xuefu Road, Zhenjiang City, Jiangsu Prov, China
}

\begin{abstract}
This article is to discuss and summarize the design steps of site design at the early stage, aiming at improving task content and implementation methods of site design, increasing information storage for practice survey. And this article discusses the innovation models of site design combination and constructs a perfect system for good site design implementation from the guidance and adjustment of design order to the specification and design of list tasks.
\end{abstract}

\section{Keywords-site design; planning and preparation; practice}

\section{INTRODUCTION}

Domestic and foreign design institutions and research centers verified that most site designs' lacking of features or highlighting too much individual consciousness has a lot to do with the attitude held by the initial designer of the construction and industry atmosphere etc. Today in the development of urbanization, we fall down in the impatient pursuit of progress and change, thinking seriously about how to "do" is the first. While for site design, it more maps in the scientific analysis on the planning and preparation at the early stage of design.

At present because of the enhancement of people's livelihood protection consciousness, site design lays emphasis on the innovation and maintenance design of site consists area as a whole so as to achieve the coordination and balance of the regional consisted human, geography elements as well as find a correlation between each other so as to achieve a symbiotic state. What's more, it is necessary to maintain, restore its existence state as far as possible to make site get benign operation with self-sustaining and ecological function. This requires designers to conduct objective and effective planning and preparation under the premise of keeping focus on the site. But planning and preparation steps in site design are not brought to the real attention. This causes some deviation from the actual, irresponsible architectures and landscape designs.

Modified site design content is composed of five sections: lead theory analysis; planning and preparation steps; special information description, analysis and evaluation; the initial expression and argumentation; final expression of design thought summary. Planning and preparation steps is the cognition part of practice at the early stage of site design, it bears the tasks of overall understanding and macro control of the site.

\section{LEAD ANALYSIS}

The arrangement of link up between five implementation sections is for the most fundamental measurement analysis so as to facilitate the later design. After the necessary theoretical analysis specifically analyze and design the water, soil, topography, vegetation and other details in site design so as to provide material for the final design expression. The work process is as follows.

\section{A. Analyze Basic Elements}

Such as analyze the built environment, natural environment--land, terrain, climate, water, vegetation, etc. and space type, the form element etc. of site to have overall understanding on site with taking the relationship between human and environment into account.

\section{B. Understand the Subjective Feeling}

Perform a description of "unforgettable site" in this section, describing the impressive site in memory. Make designer observe in the perspective of users in the form of subjective description and recalling the beginning, indirectly increasing his/her awareness of the relationship between man and site, in this preliminary analysis way, paving the way to the upcoming professional on-site analysis.

\section{Confirm the Overall Design Content and Process}

Confirm the design process including establishing design intent, conceptual thinking, development projects, detailed description and analysis, feasibility research on the site, etc. At the same time, emphasize the responsibility and the scope of services of the designer in the project.

\section{Exchange Analysis Experience}

Perform a discussion about "field" at the end of this link, including the theme of"What do you think is the most important in the site design", "Your ideal site", "When building environment, what do you think can enhance people's meaning of life " etc. Thus the overall concept comes out for site design based on three-dimensional perspective formed through investigation, analysis and subjective feeling etc. People can understand how to analyze and evaluate the site, what is more, understand how to make targeted design above the site itself.

\section{BASIC CONSIDERATIONS OF PLANNING AND PREPARATION STEPS}

Planning and preparation steps during site design take up $30 \%$ of the total while consisted of 6 links. Namely, existing background information of design selected site arranging, investigation on ecological reserve status of selected site, the basic structure of selected site residential groups, comparative analysis between selected site and similar cases, test and 
evaluate advantages and disadvantages project elements of selected site, and questionnaire summary on people living in selected site. Each link accounts for the corresponding proportion in planning and preparation steps, it is necessary to design and analyze it at a time. As Figure 1.

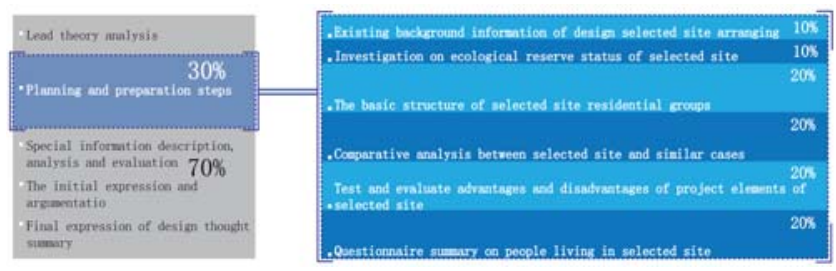

FIGURE I. PLANNING AND PREPARATION STEPS PROPORTIONAL DISTRIBUTION DIAGRAM

\section{A. Existing Background Information of Design Selected Site} Arranging(10\%)

Mainly refers to the basic site design information, including basic material such as living people, building structures, climate, vegetation, natural environment, transportation circulation etc. In this task, designers need to enter the specified area and initially record and feel the demanded site information so as to promote their growth of overall spatial awareness.

\section{B. Investigation on Ecological Reserve Status of Selected Site $(10 \%)$}

Designers investigate the environmental elements of the site such as its space geography, climate, soil, hydrology, sun angle, temperature, wind direction, topography, vegetation, road, building outline etc. and record and analysis them in detail. It is required that after field measurement and feelings, designers should show the site information of selected area in the form of profile map to form an information sheet including sun angle, wind direction, gradient and drainage etc. Purpose of the task of this part is to make designers fully understand significance and influence ecological elements and each element put on site, understand the dynamics in ecological area and ecological system knowledge. This is convenient for field test and evaluation.

\section{The Basic Structure of Selected Site Residential Groups(20\%)}

Designers know about the general picture of people groups living in or around the site, including sorting their reference information such as age, gender, nationality, family members combination modules etc. Designers be familiar with the attitude, consciousness, behavior habits, community composition, entertainment, etc. of the groups living in the site. Besides they need to communicate with groups in the designed area and know subjective demands of the groups, observe their daily life and behavior from the perspective of a user and summarize the objective requirement of a user, and finally work out the most scientific and reasonable site needs tendency.

\section{Comparative Analysis between Selected Site and Similar Cases(20\%)}

Designers need to select a case has been designed successfully and similar to designed selected site to analyze and make a comparison between the two from site information, concepts finalizing to design and construction etc. Therefore improve the predictability of design, increase scientificity of design after implementation based on the way of reference.

\section{E. Test and Evaluate Advantages and Disadvantages of Project Elements of Selected Site(20\%)}

For this part, it is necessary for designers to analyze actively the existing mutual relations between project elements have advantages and disadvantages in site design. For example, the analysis and redesign thinking of the advantages and disadvantages of every natural environmental element in the site and show them in the form of profile map. This link makes designers form a comprehensive and accurate judgment for the upcoming site. It includes not only the analysis of space, function, but also objective and subjective emotional experience during the process.

\section{F. Questionnaire Summary on People Living in Selected Site(20\%)}

Designers need to communicate with and access to family unit represents people combination to look into perception and expectation living group have for environment, and take this as important source of design data.

After team members completes the requirements of all links for planning and preparation steps, it comes to the periodic reporting and discussion of this link to review the content and process of this part.As Figure 2.

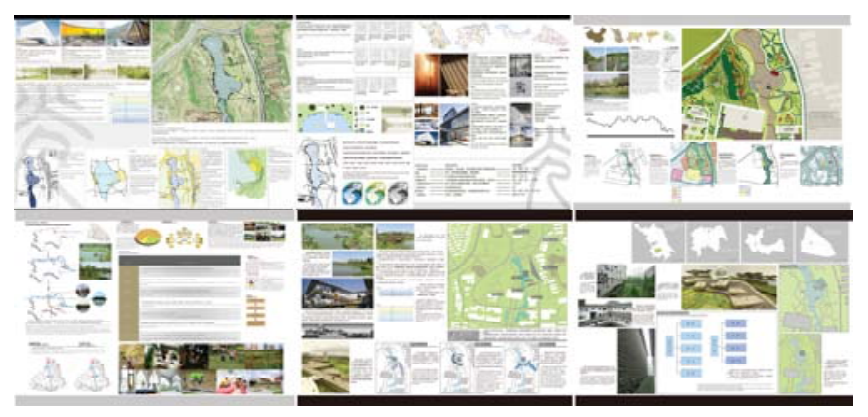

FIGURE II. PERIODIC REPORT SAMPLE OF PLANNING AND PREPARATION STEPS(WANJUN GE,YINGSUN, WEIMU MA)

Only through being personally on the scene one can have a more perceptual intuitive understanding of the specific environment for the design target and a deeper understanding of all kinds of information reflected under the environment condition. [1]Therefore, it makes design under the basis of research, and avoids "no temperature design" be divorced from reality without any emotional penetration through one-to-one correspondence between contents requirements during planning and preparation steps combined with site information got from research and the upcoming design purpose. This truly reflects the meaning of site design.

In addition to this, it is also required to issue the book of questions to designers according to the specific circumstance of site design. Please think seriously about these problems based on the circumstance that one has already had certain information reservation, and supplement content and integrate it into the design of the next step. 
Problems for examples:

1) What negative technical factors would exist in design(For example, the toxic materials, exceeding the consumption ability of land and reducing biodiversity etc.)

2) How to identify and keep and treat site(how to identify healthy and unhealthy site,treat injured site, that is, know how to balance field needs balance; know what is the basis of sustainable work formed in the site, use the speciality of usual protection strategy applicable to the important field to protect specifics such as soil, vegetation, water body, etc. by the influence of team work handling in advance).

3) How to protect site during construction(How to clearly set protect area in all construction plans to protect vegetation, soil, swamp, steep slope, surface drainage; How to set a clear protection area in using field; how to coordinate the problems such as storage, parking, performance etc. in the restricted site; How to save trees and protect healthy topsoil and avoid soil compaction etc.).

4) How to honor the life of water(how to understand natural water model, protect wounded surface water features and restore damaged water, implement special technology to balance the regional demand of water from human).

5) How to adjust the design effect by using growth power of vegetation(how to find and organize growth characteristics of local tree species and green plant species, use green plant to keep the building metope of sloping fields and covered metope need to be cooled down; how to resurrect skylines of ecological roof plants; how to design suitable structure for sustainable plant; how to select, replace and control most suitable plant species and ensure their survival and reproduction.)

6) How to use less laid to optimize public space(how to design optimization policy to reduce laying area, reduce laying area and its influence on site; how to plan the integration between infiltration runoff and pollution penetrating material originated from the laying; how to reduce the heat dissipation effect of laying area).

After thinking of these questions, basically the carrying out purpose of planning and preparation steps is completed. This plays a role of guiding the designers design thinking scientifically, improving the may be ignored and missing details in the list required in this link.

\section{CLEAR THE SIGNIFICANCE OF PLANNING AND PREPARATION STEPS DESIGN ADJUSTMENT}

The leading designers of the overall concept of planning and preparation steps in site design clearly aware of that the implementation of the expected design although relies on technical support, if they want to create sustainable design, they need to rely on the sustainable concept and technology.

\section{A. Motivation and Streamline of Research Purposes}

For site design, it is necessary to read the natural and cultural history, physical or text, of the selected site to feel the local spirit--an inner strength from the local natural process and human process, this is the essential attribute of site design should express and reflect as well as motivation and reason behind design form.[2] Different attitudes for starting point of the design determine the different final results of research. So, this site design adjustment on the one hand requires the designers to hold full respect for the site, maintain existing good place, restore the wounded place; on the other side, during the process of maintaining and restoring, designers need to understand the corresponding sustainable technologies.

\section{B. Enhanced Pertinence and Effectiveness}

Regional regulations are based on local characteristics formed by accumulation of differences of geographical conditions. All the questions in contemporary vision should be based on their own territory, that is to say, respond respectively according to geographical conditions of history, culture and reality.[3]Site design as the initial bedding link of architecture, landscape design, etc. pays more attention to keep the regionalism of site so as to make the site after design and implementation special and real.

In site design, for the overall design, clear planning and preparation steps is to fully research the site and make directional guidance. This makes designers form targeted, scientific learning thinking on the basis of fully grasping professional knowledge and prepare for the next phase.

\section{CONCLUSION}

The reform idea about design implementation is a renewal for such preliminary design concept. Integrate the concept part difficult to breakthrough in site design into planning analyzing steps through clearing the link implementation purpose, and at the same time, relying on the analysis task list. While through analysis of the planning and preparations steps before the design, designers adjust their work order of individual and cooperative group and form efficient mechanism of cooperative design and analysis, importantly, really realize the meaning of site design, on the basis of fully research and collect information.

\section{ACKNOWLEDGEMENT}

This article is the research result of 14th issue of Jian gsu University students research project (14C190).The inno vation project of training graduate student in Jiangsu provi nce(SJZZ15-0135).

\section{REFERENCES}

[1] Junhuo, Rounghan and JiayeChen, "Environmental architectural design and performance,"Liaoning art publishing house, Shenyang, 2014, pp. 127.

[2] Yukong Jian,“ck to the land,”SDX Joint Publishing Company, Beijing, 2009, pp.102.

[3] Haoda Peng, Minma,"Regional construction--publicity analysis of Huxi campus of Sichuan academy of fine arts”, Decoration, 2013.(9), pp.39. 